\title{
Adherence to Evidence-Based Therapies After Acute Coronary Syndrome: A Retrospective Population-Based Cohort Study Linking Hospital, Outpatient, and Pharmacy Health Information Systems in Valencia, Spain
}

\author{
Gabriel Sanfélix-Gimeno, PharmD, PhD; Salvador Peiró, MD, PhD; Inma Ferreros, BSc; \\ Raquel Pérez-Vicente, BSc; Julián Librero, MD, PhD; Ferrán Catalá-López, PharmD, PhD; \\ Francisco Ortiz, MD; and Vicent Tortosa-Nácher, MD
}

\begin{abstract}
BACKGROUND: Pharmacological secondary prevention in patients after an acute coronary syndrome (ACS) has contributed substantially to reductions in cardiovascular morbidity and mortality and, overall, has undergone important improvements in recent years. Nevertheless, there is still a considerable adherence gap and opportunity for improvement.
\end{abstract}

OBJECTIVE: To assess, in a cohort of patients who survived an ACS, adherence to commonly prescribed secondary prevention drugs, factors associated to adherence, and variations among health care delivery areas.

METHODS: We combined the medical and pharmacy databases from a regional public health service in Valencia, Spain, to construct a populationbased cohort of patients discharged alive after an emergency admission for an ACS to any hospital of the Valencia Health Agency in 2008. We evaluated medication adherence by determining the proportion of days covered (PDC) for each therapeutic group (antiplatelet agents, beta-blockers, angiotensin antagonists, and statins) in the 9 months following hospital discharge. Fully adherent patients were defined as those having enough treatment to cover $75 \%$ (PDC75) of the follow-up period.

RESULTS: The study cohort consisted of 7,462 patients. PDC75 was reached by $69.9 \%$ of patients taking antiplatelet agents, $43.3 \%$ taking beta-blockers, $45.4 \%$ taking angiotensin antagonists, and $58.8 \%$ taking statins. Approximately $18 \%$ of patients did not reach PDC75 with any treatment, while $47.6 \%$ did so for 3 or more therapeutic groups. Lower adherence was found in diagnoses other than myocardial infarction. Other factors associated with nonadherence were older age, women, having copayment, foreign born, and most comorbidities (except for hypertension and hyperlipidemia, which were inversely associated, and diabetes and peripheral disease, which were not significantly associated). Health care delivery areas showed certain variability in their performance on these adherence measures that remained after the adjustment for covariates, although confidence intervals overlapped except between areas at the extremes.

CONCLUSIONS: The proportion of fully adherent patients remains suboptimal, and important improvements are still possible in secondary prevention of ischemic heart disease. The combination of electronic health information systems may be very useful for monitoring adherence and evaluating the effectiveness of adherence and other quality improvement interventions.

J Manag Care Pharm. 2013;19(3):247-57

Copyright $\odot 2013$, Academy of Managed Care Pharmacy. All rights reserved.

\section{What is already known about this subject}

- The use of evidence-based medical therapies has contributed substantially to reductions in cardiovascular morbidity and mortality, and for patients with acute coronary syndrome (ACS), the prescription of these highly effective therapies at the time of hospital discharge has improved worldwide. However, there is still a need to improve adherence and subsequent ACS secondary prevention outcomes.

- Guidelines recommend these therapies be used on a continuous basis and indefinitely. The extremely important role of adherence to these therapies in morbidity and mortality in patients after an ACS has been widely described

- Typically, studies have focused on the rates of appropriate prescriptions, but the extent to which prescribed therapies are maintained over time and its predictors has received less attention, especially in the Spanish setting.

\section{What this study adds}

- The combination of electronic databases (e.g., hospital discharge datasets, ambulatory electronic medical records, electronic prescribing systems, and pharmaceutical dispensation records) available in this study allowed the assessment of adherence and its predictors, suggesting that this strategy could be used to monitor adherence and to evaluate the effectiveness of adherence and other quality improvement interventions.

- Adherence to evidence-based medical therapies in post-ACS patients remains suboptimal.

- Our finding of lower adherence in diagnoses other than myocardial infarction is striking and should be studied further.

\footnotetext{
A lthough recent studies indicate a reduction in incidence ${ }^{1}$ coronary heart disease (CHD) remains the leadLing cause of death in Spain ${ }^{2}$ and other developed countries. $^{3}$ Numerous large-scale prospective randomized trials involving hundreds of thousands of patients have documented the efficacy and safety of several treatments for patients with myocardial infarction (MI) and other forms of acute coronary syndrome (ACS). Practice guidelines recommend that, unless a relevant contraindication exists, post-MI patients receive
} 


\section{Adherence to Evidence-Based Therapies After Acute Coronary Syndrome: A Retrospective Population-Based Cohort Study Linking Hospital, Outpatient, and Pharmacy Health Information Systems in Valencia, Spain}

treatment with antiplatelet agents, such as aspirin or clopidogrel; beta-blockers; angiotensin antagonists, such as angiotensin-converting enzyme inhibitors (ACEI) or angiotensin receptor blockers (ARB); and lipid-lowering statins. ${ }^{4}$ Taken in combination, these drugs have been estimated to reduce the relative risk of CHD mortality by $80 \%$ as compared with placebo. ${ }^{5}$ For the United States, it has been estimated that secondary prevention contributed to an $11 \%$ decrease in the number of coronary deaths from 1980 to $2000 .{ }^{6}$

Despite the large amount of evidence supporting the use of professional recommendations and the development of public policies leading to significant improvements in ACS management and its consequences in recent years, several studies have documented underprescribing and low adherence to evidence-based therapies after an ACS. ${ }^{7-11}$ In Spain, a review of observational studies from 1995 to 2004 showed a significant improvement in the proportion of post-MI patients with these treatments at hospital discharge, during the immediate post-discharge follow-up, and in the primary care setting. ${ }^{12}$ Nevertheless, there is still a considerable need for improving preventive care in patients with CHD. ${ }^{13}$

Studies evaluating the utilization of pharmacological treatment after ACS mostly use 2 research designs: (1) prospective or retrospective cohort hospital-based designs to determine the rate of treatment in patients discharged alive after an ACS, usually at the moment of discharge and in some cases after a pre-defined follow-up period, and (2) cross-sectional primary care-based designs to assess prescribed treatments in patients who previously have had an ACS. Both designs require large samples with expensive fieldwork. Additionally, these studies usually focus on the rates of appropriate prescriptions, but the extent to which prescribed therapies are maintained over time has received less attention. It should be noted that adherence to a combination of evidence-based medical therapies is strongly associated with lower mortality in patients after an ACS, ${ }^{14-18}$ and guidelines recommend these therapies be used indefinitely. ${ }^{4}$

At present, most of the information necessary for guiding quality improvement policies in CHD secondary prevention is available in electronic databases that store data from hospital discharge, electronic medical records, physician order entry systems, electronic prescribing systems, and pharmaceutical dispensation records. Data stored in these information systems, conveniently combined and not without some bias, allow the construction of cohorts and the evaluation, with varying strength, of prescription rates and long-term adherence. Our aim in this study was to assess, in a cohort of patients who survived an ACS, adherence to commonly prescribed secondary prevention drugs, its predictors, and variations in adherence among health care areas.

\section{Methods}

\section{Design}

We combined the databases from a public regional health service in Spain to construct a population-based cohort of patients discharged alive after an emergency admission for ACS to any hospital of the Valencia Health Agency (VHA) in 2008. Patients were followed throughout the health information systems for 9 months after hospital discharge to assess adherence to 4 therapeutic groups: antiplatelet agents, beta-blockers, drugs acting on the renin-angiotensin system (ACEI or ARB), and statins.

\section{Setting}

The study was conducted in the Valencia Community, an autonomous region in Spain with 5 million inhabitants in 2008. Like all of the regional health care systems in Spain, ${ }^{19}$ the VHA operates an extensive hospital (84\% of the hospital beds in the region, including several university hospitals) and health care center network, which covers about $97 \%$ of the regional population. Medical care in this network is free of charge, with coverage extending to substantial pharmaceutical benefits: all medicines prescribed to pensioners (eligible because of either age or disability) and underprivileged groups are free of charge. The remaining population pays $40 \%$ of the cost of medication (but only $10 \%$, with a ceiling of $€ 2.45$ ( $\approx \$ 3$ USD) for long-term treatments, such as most cardiovascular drugs).

Some features of the prescription and dispensing system in the VHA are relevant to our study:

1. Prescriptions must be filled out on a specific Spanish National Health System form.

2. Medications are always dispensed by pharmacies in the manufacturers' original packages and not in unit-dose packages customized for individual patient needs.

3. A separate prescription form must be filled out for each package, and each prescription is only valid within 10 days of its issue date. In the case of long-term prescriptions, the electronic medical record system calculates doses and prints as many prescription forms-with successive dates depending on the dose and the units in the package-as necessary to cover the period indicated by the physician.

4. Prescription forms, even when the first one is indicated by a specialist, must be renewed by the general practitioner throughout the duration of treatment.

5. Pharmacies present the claims for the dispensed drugs electronically once a month. Among other data, these electronic claims include information about the drug dispensed (brand name, formulation, dose, and number of units) and the patient identification number.

6. There are no negative drug formularies, and the VHA covers practically all authorized (except over-the-counter) medications. It should be noted that clopidogrel is subject to prior authorization (having had an ACS is adequate criterion to prescribe it). 


\section{Adherence to Evidence-Based Therapies After Acute Coronary Syndrome: A Retrospective Population-Based Cohort Study Linking Hospital, Outpatient, and Pharmacy Health Information Systems in Valencia, Spain}

The VHA provides several information systems, which were used in this study:

1. The Population Information System, called SIP, provides an identification number for each person under VHA coverage and registers some demographic characteristics (e.g., age, gender, country of origin, copayment status, etc.) and dates and causes of VHA discharge, including death.

2. The Minimum Basic Dataset (MBDS) at hospital discharge is a synopsis of clinical and administrative information on all hospital discharges, including diagnoses and procedures (all electronic health systems in the VHA use the International Classification of Diseases, Ninth Revision, Clinical Modification [ICD-9-CM]).

3. The electronic medical record for ambulatory care, called ABUCASIS, is available in all primary health care centers and other ambulatory settings.

4. The pharmaceutical module, called GAIA, part of ABUCASIS, includes information about physician prescriptions and dispensations from pharmacy claims.

All the information in these systems can be linked at the individual level through the SIP number. The singular nature and ubiquity of the Valencia Health Information System prevents some misclassification and measurement errors associated with lack of complete data. Also, this health information system allows differentiation between prescription (what the doctor prescribed) and dispensing (what the patient fills from the pharmacy), an aspect that may be of interest for the design of practice policies.

\section{Population}

All patients of both sexes aged 35 years and over, admitted through the Emergency Department and discharged alive in any VHA hospital with a main diagnosis of ACS (ICD-9-CM: 410.xx acute MI, 411.xx other acute and subacute forms of ischemic heart disease [IHD], 413.xx angina pectoris, and 414.xx other forms of chronic IHD) between January 1, 2008, and December 31,2008 , were included. We excluded deaths in the 30 days following hospital discharge, duplicate cases (if the patient had more than 1 ACS admission, only the first was accounted for), some government employees whose prescriptions are reimbursed by civil service insurance mutualities (not included in the pharmacy databases of the VHA), and patients not registered in the municipal census, who left the region or who were discontinued from VHA coverage because of limitations on follow-up. The final cohort comprised patients who had at least 1 visit to the primary care physician and at least 1 prescription of 1 or more of the 4 drug classes within the 9 months after index hospitalization to diminish bias due to loss to follow-up.

\section{Primary Endpoint}

We identified adherence to therapy based on pharmacy claims according to an ascertainment period of 9 months after dis- charge for an ACS diagnosis. Drugs from the 4 therapeutic classes were selected using the GAIA module through the following codes of the anatomical therapeutic chemical (ATC) classification: (a) antiplatelet agents, including acetylsalicylic acid (ASA) at doses of 100 milligrams (mg; ATC: B01AC06), and clopidogrel (ATC: B01AC04); (b) beta-blockers (ATC: C07); (c) ACEI alone or in combination (ATC: C09A, C09B) and ARB alone or in combination (ATC: C09C, C09D); and (d) statins (ATC: C10AA).

We evaluated adherence by determining the proportion of days covered (PDC) for each therapeutic group. PDC is a widely used adherence metric calculated by dividing the number of days of medication supplied by the number of days in a given period..$^{10,20,21}$ PDC, by construction, is synonymous with the medication possession ratio capped at $100 \%$ used in some studies. For our analysis, we use the sum of days of dispensed medication from the date of hospital discharge up to 270 days following discharge as the PDC numerator. Drugs from the same therapeutic group (i.e., aspirin and clopidogrel, ACEI and ARB) in overlapping periods were accounted for only once. Treatment days were censored if they exceeded the final date of follow-up. The PDC denominator was the sum of days from the date of discharge up to 270 days following discharge or the date of death (in the case of death during the follow-up, we used only the days of real follow-up to calculate the PDC).

On the basis of their PDCs, we classified patients as fully adherent $(\geq 75 \%)$ and partially or nonadherent $(<75 \%)$. We opted for a PDC75 because in the Spanish prescription system, with a follow-up of 9 months and for most of the medications analyzed, a cut-off point of $80 \%$ becomes a factual cut-off point near $90 \%$ (8 packages with doses typically for 1 month in 9 months $=88.9 \%$ of days covered). The chosen PDC75 (7 packages in 9 months $=77.8 \%$ of days covered) was more comparable to the commonly used PDC80. To assess simultaneous adherence to various medications, we also calculated 2 combined measures: the proportion of patients reaching PDC75 for the combination of 3 or more therapeutic classes and the proportion of patients not reaching PDC75 in any of the 4 therapeutic groups. The number of days of treatment was calculated assuming that 1 tablet of ASA, clopidogrel, or statins was equivalent to 1 day of treatment. In the case of beta-blockers and ACEI or ARB, we used the dosing schedule specified in the prescription (1 tablet every 8,12 , or 24 hours). When this did not agree with standard dosing (around $1 \%$ of cases), we rounded the dosing prescribed to the closest frequency $(8,12$, or 24 hours).

\section{Covariates}

We searched sociodemographic and clinical data from the electronic medical records and the hospital MBDS. In addition to the main discharge diagnosis for hospital admission (ICD-9-CM 410: acute MI, 411: other acute and subacute forms 


\section{Adherence to Evidence-Based Therapies After Acute Coronary Syndrome: A Retrospective Population-Based Cohort Study Linking Hospital, Outpatient, and Pharmacy Health Information Systems in Valencia, Spain}

of IHD, 413: angina pectoris, and 414: other forms of chronic IHD), we identified the following variables: age at hospital admission; sex; country of birth (coded as Spain or other); presence of chronic conditions (hypertension, hyperlipidemia, diabetes, smoking, arrhythmias, congestive heart failure, chronic obstructive pulmonary disease [COPD], chronic kidney disease, cerebrovascular disease, dementia, and cancer); and the health care delivery area of patient residence (in 2008 the VHA was organized into 23 geographical territories, each served by a hospital). Health care delivery area of patient residence does not necessarily correspond to the hospital where the patient was treated during the acute admission.

\section{Ethics}

The study protocol was approved by the Ethics and Clinical Trials Committee of the "Dirección General de Salud Pública y Centro Superior de Investigación en Salud Pública" (CEIC DGSP-CSISP, report of September 30, 2009). In accordance with the authorized protocol, the database linkages were carried out in the Health Agency Information Department of the VHA by the people authorized to do these tasks. To protect patient privacy, data were sent to the researchers with dissociate nontraceable codes that did not allow the identification of individual patients.

\section{Analysis}

Cohort characteristics and outcome measures were described using proportions with their corresponding 95\% confidence intervals (CI) and calculated through the binomial method. Medication adherence (PDC75) for the 4 therapeutic groups studied according to sociodemographic and clinical characteristics was compared using the chi square test. The differences in the summary measures (proportion of patients reaching PDC75 for the combination of 3 or more therapeutic classes and the proportion of patients not reaching PDC75 in any of the 4 therapeutic groups) with regard to sociodemographic and clinical characteristics were also assessed through the chi square test. Two multivariable logistic regression models were built for both dependent summary variables to evaluate the strength of the association between them and the sociodemographic and clinical characteristics and to construct 2 propensity scores. We constructed an initial model with all covariates and used the backward-stepwise technique, with a removing probability of 0.10 and an entry probability of 0.05 to retain the significant variables. The fit-of-the-model was evaluated using the $\mathrm{C}$-statistic (the area below the receiver operating characteristic [ROC] curve) for discrimination and the Hosmer-Lemeshow test for calibration. Differences between health care areas were assessed for both summary measures using logistic regression adjusting by the respective propensity score. Odds ratios with their corresponding 95\% CI were represented graphically. All statistical analyses were performed using the STATA 10.0 (Stata Corp., College Station, TX) statistical software.

\section{FIGURE 1) Study Scheme}

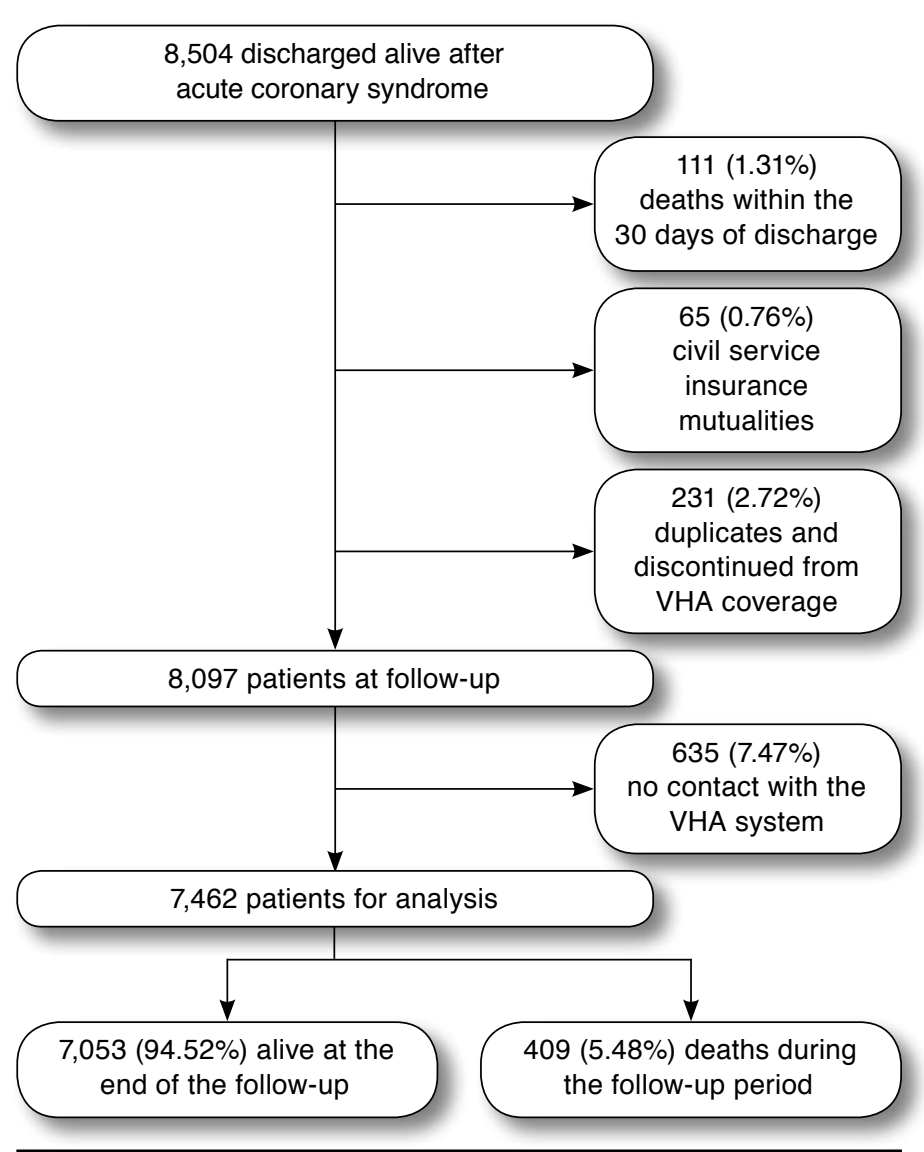

VHA: Valencia Health Agency.

\section{Results}

From 8,504 patients discharged alive after an ACS hospital admission, we excluded 111 patients who died in the 30 days following hospital discharge, 65 patients with reimbursed prescriptions from civil service insurance mutualities, 231 patients discontinued from VHA coverage, and 635 patients with no contact with the VHA's health care system in the follow-up period, leaving 7,462 (87.7\%) patients for analysis who had at least 1 prescription written for 1 or more of the 4 drug classes (Figure 1). Patients aged 65 years and over accounted for $67 \%$ of the total (mean age at admission: 68.8 years; $95 \%$ CI: 68.5-69.0). Approximately 70\% were male; $89 \%$ were born in Spain; and $75 \%$ were pensioners (pharmaceutical copayment not required) at the end of the follow-up period (Table 1). The most frequent main diagnosis was acute MI (50.7\%) followed by other forms of chronic IHD (19.0\%), other acute and subacute forms of IHD (15.3\%), and angina pectoris (14.9\%). A high proportion of patients had risk factors or comorbidities: hypertension (62.8\%), dyslipidemia (42.0\%), diabetes (34.5\%), smoking (24.8\%), arrhythmias (21.0\%), and heart failure 


\section{Adherence to Evidence-Based Therapies After Acute Coronary Syndrome: A Retrospective Population-Based Cohort Study Linking Hospital, Outpatient, and Pharmacy Health Information Systems in Valencia, Spain}

\begin{tabular}{|c|c|c|c|}
\hline & & n & $\%$ \\
\hline \multirow[t]{4}{*}{$\overline{\text { Age }}$} & $<45$ years & 295 & 3.95 \\
\hline & 45 to 64 & 2,431 & 32.58 \\
\hline & 65 to 79 & 3,055 & 40.94 \\
\hline & 80 and over & 1,681 & 22.53 \\
\hline \multirow[t]{2}{*}{ Sex } & Men & 5,160 & 69.15 \\
\hline & Women & 2,302 & 30.85 \\
\hline \multirow{2}{*}{$\begin{array}{l}\text { Country of } \\
\text { birth }\end{array}$} & Spain & 6,644 & 89.04 \\
\hline & Other & 818 & 10.96 \\
\hline \multirow{2}{*}{$\begin{array}{l}\text { Free } \\
\text { pharmaceuticals }\end{array}$} & No & 1,867 & 25.02 \\
\hline & Yes & 5,595 & 74.98 \\
\hline \multirow{4}{*}{$\begin{array}{l}\text { Main } \\
\text { diagnosis }\end{array}$} & AMI & 3,783 & 50.70 \\
\hline & Other acute and subacute forms of IHD & 1,144 & 15.33 \\
\hline & Angina pectoris & 1,115 & 14.94 \\
\hline & Other forms of chronic IHD & 1,420 & 19.03 \\
\hline \multirow{12}{*}{$\begin{array}{l}\text { Secondary } \\
\text { diagnosis }\end{array}$} & Hypertension & 4,683 & 62.76 \\
\hline & Hyperlipidemia & 3,134 & 42.00 \\
\hline & Diabetes & 2,576 & 34.52 \\
\hline & Smoking & 1,848 & 24.77 \\
\hline & Arrhythmias & 1,568 & 21.01 \\
\hline & Heart failure & 1,083 & 14.51 \\
\hline & COPD & 554 & 7.42 \\
\hline & Chronic renal failure & 376 & 5.04 \\
\hline & Peripheral vascular disease & 257 & 3.44 \\
\hline & Stroke & 200 & 2.68 \\
\hline & Dementia & 76 & 1.02 \\
\hline & Cancer & 65 & 0.87 \\
\hline \multicolumn{2}{|l|}{ Total } & 7,462 & 100.00 \\
\hline \multicolumn{4}{|c|}{$\begin{array}{l}A M I=\text { acute myocardial infarction } ; C O P D=\text { chronic obstructive pulmonary disease; } \\
I H D=\text { ischemic heart disease }\end{array}$} \\
\hline
\end{tabular}

(14.5\%). Four hundred and nine patients (5.5\%) died during the follow-up (520 including the 111 deaths in the first month post-discharge).

The average PDC for the main cohort of analysis (patients with at least 1 prescription for 1 or more drug classes) was 76.5\% (95\% CI: 75.8-77.3) for antiplatelet agents, 54.2\% (95\% CI: 53.2-55.1) for beta-blockers, 56.0\% (95\% CI: 55.1-56.9) for ACEI/ARB, and 67.9\% (95\% CI: 67.1-68.8) for statins. For these patients, PDC75 was reached by $69.9 \%$ for antiplatelet drugs, $43.3 \%$ for beta-blockers, $45.4 \%$ for ACEI or ARB, and $58.8 \%$ for statins (Table 2). Regarding the prescription of these medications after ACS, $92.8 \%(n=6,928)$ of patients received an antiplatelet prescription post-discharge; $74.7 \%(n=5,575)$ received a prescription for beta-blockers; $77.2 \%(n=5,760)$ received a prescription for ACEI or ARB; and 87.1\% ( $\mathrm{n}=6,499)$ received a prescription for statins. Among these (patients with at least 1 prescription of each drug class), $75.3 \%$ reached PDC75 for antiplatelets; $57.9 \%$ reached PDC75 for beta-blockers; $58.8 \%$ reached PDC75 for ACEI or ARB; and 67.5\% reached PDC75 for statins.

In general, getting enough treatment to reach PDC75 was associated with age (less treatment in people under 45 years), sex (more antiplatelet agents in men but lower ACEI/ARB),
TABLE 2 Percentage of Patients Treated for $75 \%$ or More of the Follow-Up Period

\begin{tabular}{|c|c|c|c|c|c|}
\hline \multicolumn{2}{|c|}{$\mathrm{N}=7,462$} & $\begin{array}{c}\text { Antiplatelet } \\
\text { Agents }\end{array}$ & $\begin{array}{l}\text { ACEI/ } \\
\text { ARB }\end{array}$ & $\begin{array}{c}\text { Beta- } \\
\text { Blockers }\end{array}$ & Statins \\
\hline \multirow[t]{4}{*}{ Age (in years) } & $<45$ & $61.69^{a}$ & $28.81^{a}$ & $37.63^{a}$ & $42.71^{\mathrm{a}}$ \\
\hline & 45 to 64 & 71.12 & 41.42 & 45.87 & 57.88 \\
\hline & 65 to 79 & 72.44 & 49.69 & 45.79 & 64.52 \\
\hline & 80 and over & 65.08 & 46.34 & 35.87 & 52.53 \\
\hline \multirow[t]{2}{*}{ Sex } & Men & $71.41^{\mathrm{a}}$ & $44.38^{b}$ & 43.31 & 59.38 \\
\hline & Women & 66.59 & 47.74 & 43.14 & 57.47 \\
\hline \multirow{4}{*}{$\begin{array}{l}\text { Main } \\
\text { diagnosis }\end{array}$} & AMI & $74.09^{a}$ & 46.81 & $44.30^{\mathrm{a}}$ & $61.78^{a}$ \\
\hline & $\begin{array}{l}\text { Other acute and } \\
\text { subacute forms } \\
\text { of IHD }\end{array}$ & 68.53 & 45.02 & 41.78 & 56.38 \\
\hline & Angina pectoris & 55.07 & 44.04 & 37.94 & 49.96 \\
\hline & $\begin{array}{l}\text { Other forms of } \\
\text { chronic IHD }\end{array}$ & 71.62 & 43.10 & 45.85 & 59.72 \\
\hline \multirow{2}{*}{$\begin{array}{l}\text { Free } \\
\text { pharmaceuticals }\end{array}$} & No & $67.22^{b}$ & $36.10^{a}$ & 42.05 & $50.88^{a}$ \\
\hline & Yes & 70.83 & 48.53 & 43.66 & 61.43 \\
\hline \multirow{2}{*}{$\begin{array}{l}\text { Country of } \\
\text { birth }\end{array}$} & Spain & $71.10^{\mathrm{a}}$ & $46.34^{a}$ & 43.65 & $59.69^{a}$ \\
\hline & Other & 60.39 & 37.90 & 40.10 & 51.47 \\
\hline \multirow{12}{*}{$\begin{array}{l}\text { Secondary } \\
\text { diagnosis }\end{array}$} & Hypertension & 69.83 & $52.15^{a}$ & 43.80 & $59.71^{b}$ \\
\hline & Hyperlipidemia & $72.59^{a}$ & $46.78^{\mathrm{b}}$ & $46.23^{a}$ & $64.87^{\mathrm{a}}$ \\
\hline & Diabetes & 69.49 & $51.28^{a}$ & $45.23^{b}$ & 59.55 \\
\hline & Smoking & 71.10 & $38.69^{a}$ & $41.45^{b}$ & $55.95^{\mathrm{b}}$ \\
\hline & Arrhythmias & $62.88^{a}$ & 46.56 & $36.61^{\mathrm{a}}$ & $54.78^{a}$ \\
\hline & Heart failure & $65.10^{\mathrm{a}}$ & 47.18 & 41.46 & $53.37^{a}$ \\
\hline & COPD & 66.43 & $40.79^{b}$ & $24.19^{b}$ & $51.62^{a}$ \\
\hline & $\begin{array}{l}\text { Chronic renal } \\
\text { failure }\end{array}$ & $61.44^{a}$ & $39.89^{b}$ & $36.70^{\mathrm{b}}$ & $51.06^{\mathrm{b}}$ \\
\hline & $\begin{array}{l}\text { Peripheral } \\
\text { vascular disease }\end{array}$ & 71.21 & 42.41 & 41.25 & 58.75 \\
\hline & Stroke & $57.50^{\mathrm{a}}$ & $37.00^{\mathrm{b}}$ & $35.50^{\mathrm{b}}$ & 53.00 \\
\hline & Dementia & $52.63^{a}$ & 43.42 & $21.05^{\mathrm{a}}$ & $35.53^{a}$ \\
\hline & Cancer & $58.46^{\mathrm{b}}$ & $26.15^{\mathrm{b}}$ & 33.85 & $46.15^{b}$ \\
\hline Total & & 69.93 & 45.42 & 43.26 & 58.79 \\
\hline
\end{tabular}

$a P<0.001$.

${ }^{b} P<0.05$

$A C E I=$ angiotensin-converting enzyme inhibitors; $A M I=$ acute myocardial infarction; $A R B=$ angiotensin receptor blockers; $C O P D=$ chronic obstructive pulmonary disease; $I H D=$ ischemic heart disease.

main diagnosis of acute MI, no copayment, and Spain as country of origin. Regarding comorbidities, it is worth pointing out that patients with dementia, cancer, stroke, chronic renal failure, and COPD were more likely to be nonadherent. Approximately $18 \%$ of patients did not reach PDC75 with any treatment (Table 3), while $47.6 \%$ did so for 3 or more therapeutic groups. In the bivariate analysis, factors associated with achieving PDC75 with 3 or more drugs were very similar to those previously described.

Table 4 shows the results of the logistic regression models used to construct 2 propensity scores regarding the achievement of PDC75 with 3 or more therapeutic groups or with none of the therapeutic groups. The associations found in these models were similar to those described for the bivariable 


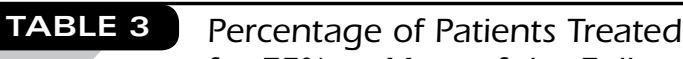

for $75 \%$ or More of the Follow-

Up Period with 3 or More Drugs, and with None of Them

\begin{tabular}{|c|c|c|c|}
\hline \multicolumn{2}{|r|}{$\mathrm{N}=7,462$} & $\begin{array}{l}3 \text { or More } \\
\text { Drugs }\end{array}$ & 0 Drugs \\
\hline \multirow[t]{4}{*}{ Age (in years) } & $<45$ & $33.22^{\mathrm{a}}$ & $29.83^{a}$ \\
\hline & 45 to 64 & 47.31 & 18.51 \\
\hline & 65 to 79 & 52.70 & 14.66 \\
\hline & 80 and over & 41.05 & 19.75 \\
\hline \multirow[t]{2}{*}{ Sex } & Men & 48.29 & 17.89 \\
\hline & Women & 45.87 & 17.16 \\
\hline \multirow[t]{4}{*}{ Main diagnosis } & AMI & $51.41^{\mathrm{a}}$ & $16.89^{a}$ \\
\hline & $\begin{array}{l}\text { Other acute and subacute } \\
\text { forms of IHD }\end{array}$ & 45.37 & 17.92 \\
\hline & Angina pectoris & 35.61 & 21.79 \\
\hline & Other forms of chronic IHD & 48.38 & 16.27 \\
\hline \multirow{2}{*}{$\begin{array}{l}\text { Free } \\
\text { pharmaceuticals }\end{array}$} & No & $41.72^{\mathrm{a}}$ & $23.35^{a}$ \\
\hline & Yes & 49.49 & 15.76 \\
\hline \multirow{2}{*}{$\begin{array}{l}\text { Country of } \\
\text { birth }\end{array}$} & Spain & $48.25^{a}$ & $16.38^{a}$ \\
\hline & Other & 41.81 & 28.12 \\
\hline \multirow{12}{*}{$\begin{array}{l}\text { Secondary } \\
\text { diagnosis }\end{array}$} & Hypertension & $50.16^{a}$ & $16.27^{\mathrm{a}}$ \\
\hline & Hyperlipidemia & $51.95^{\mathrm{a}}$ & $15.79^{\mathrm{a}}$ \\
\hline & Diabetes & $50.16^{\mathrm{a}}$ & $16.07^{\mathrm{b}}$ \\
\hline & Smoking & $44.48^{b}$ & $20.62^{\mathrm{a}}$ \\
\hline & Arrhythmias & $40.63^{a}$ & 19.20 \\
\hline & Heart failure & $43.77^{\mathrm{b}}$ & 19.67 \\
\hline & COPD & $35.02^{\mathrm{a}}$ & $23.10^{\mathrm{a}}$ \\
\hline & Chronic renal failure & $37.77^{\mathrm{a}}$ & $22.07^{\mathrm{b}}$ \\
\hline & Peripheral vascular disease & 44.75 & 16.73 \\
\hline & Stroke & $36.00^{a}$ & $28.00^{a}$ \\
\hline & Dementia & $28.95^{\mathrm{a}}$ & $34.21^{\mathrm{a}}$ \\
\hline & Cancer & $35.38^{b}$ & $39.23^{b}$ \\
\hline \multicolumn{2}{|l|}{ Total } & 47.55 & 17.66 \\
\hline \multicolumn{4}{|l|}{$\begin{array}{l}a P<0.001 \\
b P<0.05\end{array}$} \\
\hline
\end{tabular}

analysis except for sex (lower adherence in women in 1 of the models while that factor was not significant in the bivariable analysis) and the presence of diabetes or arrhythmias (not significant in the multivariable models). The models show a moderate goodness-of-fit, with a discrete discriminative capacity (C-statistics $=0.63$ for both models) and good calibration in the case of the model with PDC75 for 3 or more therapeutic groups but deficient in the model for PDC75 for none of the groups.

Among health care delivery areas, the raw proportion of patients reaching PDC75 with the combinations of 3 or 4 therapeutic classes ranged between $58.1 \%$ and $38.0 \%(P<0.001)$. The raw proportion of patients who did not reach PDC75 with any of the 4 therapeutic groups ranged from $9.4 \%$ to 29.3\% $(P<0.001)$. Figure 2 compares both combined measures among areas once adjusted for the respective propensity scores (Table 4) using the health care area in the median as the reference. Although the differences between areas are impor-
FIGURE 2 Adherence Among Health Areas: Patients Reaching PDC75 with 3 or More Therapeutic Groups, and with None of Them ${ }^{\text {a }}$

A. Patients Reaching the PDC75 with 3+ Therapeutic Groups

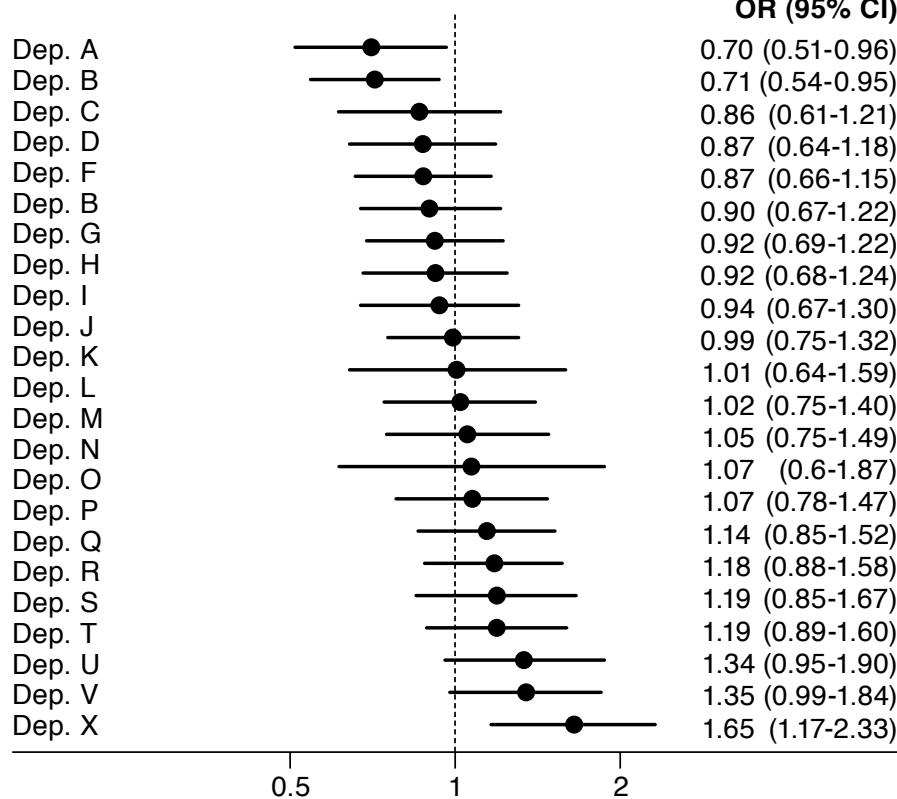

B. Patients Not Reaching the PDC75 with Any Therapeutic Group

Dep. A

Dep. B

Dep. C

Dep. D

Dep. F

Dep. B

Dep. G

Dep. $\mathrm{H}$

Dep. I

Dep. J

Dep. K

Dep. L

Dep. M

Dep. N

Dep. O

Dep. $P$

Dep. Q

Dep. R

Dep. S

Dep. T

Dep. U

Dep. V

Dep. $X$

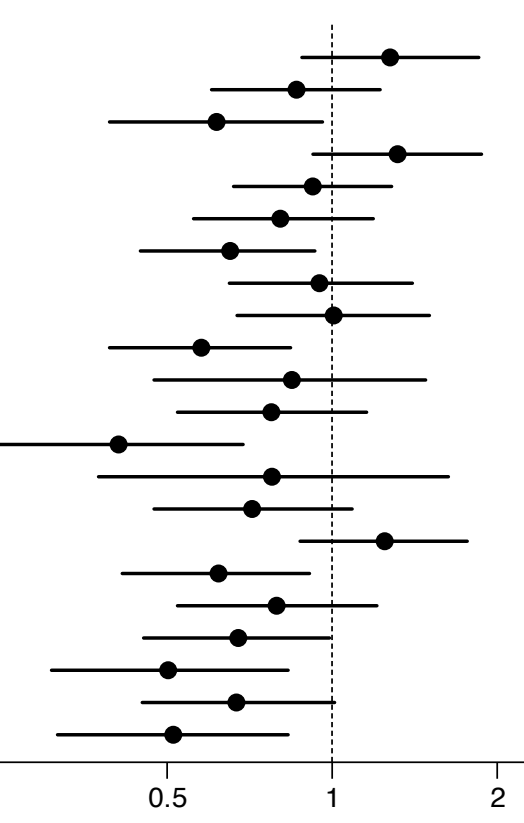

OR $(95 \% \mathrm{Cl})$

$1.27(0.88-1.83)$

$0.85(0.60-1.22)$

$0.61(0.39-0.96)$

$1.31(0.91-1.87)$

$0.92(0.66-1.28)$

$0.80(0.55-1.18)$

$0.64(0.44-0.93)$

$0.95(0.65-1.39)$

$1.00(0.67-1.50)$

$0.57(0.39-0.83)$

$0.83(0.47-1.48)$

$0.77(0.52-1.15)$

$0.40(0.24-0.68)$

$0.77(0.37-1.61)$

$0.71(0.47-1.08)$

$1.24(0.88-1.76)$

$0.61(0.41-0.90)$

$0.78(0.50-1.20)$

$0.66(0.45-0.97)$

$0.50(0.30-0.82)$

$0.66(0.44-0.99)$

$0.51(0.31-0.82)$

The vertical line indicates the area's median for PDC75 with 3 or more drugs.

${ }^{a} \mathrm{Odd}$ ratio adjusted by propensity scores.

$C I=$ confidence interval $; P D C=$ proportion of days covered; $O R=$ odds ratio. 


\section{Adherence to Evidence-Based Therapies After Acute Coronary Syndrome: A Retrospective Population-Based Cohort Study Linking Hospital, Outpatient, and Pharmacy Health Information Systems in Valencia, Spain}

TABLE 4 Logistic Regression Analysis: Patients Treated for $75 \%$ or More of the FollowUp Period with 3 or More Drugs, and with None of Them

\begin{tabular}{l|l|c|c|c|c}
\hline \multicolumn{2}{c|}{} & \multicolumn{2}{|c|}{3 or More Drugs } & \multicolumn{2}{c}{ D Drugs $^{\mathrm{b}}$} \\
\cline { 3 - 6 } \multicolumn{2}{c|}{} & OR & $95 \%$ CI & OR & $95 \%$ CI \\
\hline \multirow{3}{*}{ Age (in years) } & $<45$ & 1.00 & & 1.00 & \\
\cline { 2 - 6 } & 45 to 64 & 1.54 & $1.33-1.78$ & 0.62 & $0.52-0.75$ \\
\cline { 2 - 6 } & 65 to 79 & 1.51 & $1.34-1.70$ & 0.71 & $0.61-0.83$ \\
\hline \multirow{2}{*}{ Sex } & Men & 1.00 & & \multicolumn{3}{|}{} \\
\hline & Women & 0.83 & $0.75-0.93$ & \multicolumn{3}{|c}{} \\
\hline
\end{tabular}

\begin{tabular}{|c|c|c|c|c|c|}
\hline \multicolumn{6}{|l|}{ Main diagnosis } \\
\hline \multicolumn{2}{|l|}{$\overline{\mathrm{AMI}}$} & 1.00 & & 1.00 & \\
\hline \multicolumn{2}{|c|}{$\begin{array}{l}\text { Other acute and subacute } \\
\text { forms of IHD }\end{array}$} & 0.70 & $0.61-0.81$ & 1.19 & $1.01-1.42$ \\
\hline \multicolumn{2}{|l|}{ Angina pectoris } & 0.46 & $0.39-0.53$ & 1.59 & $1.35-1.88$ \\
\hline \multicolumn{2}{|c|}{ Other forms of chronic IHD } & 0.74 & $0.65-0.84$ & & \\
\hline \multirow{2}{*}{$\begin{array}{l}\text { Free } \\
\text { pharmaceuticals }\end{array}$} & No & 1.00 & & 1.00 & \\
\hline & Yes & 1.68 & $1.45-1.95$ & 0.52 & $0.43-0.63$ \\
\hline \multirow[t]{2}{*}{ Country of birth } & Other & 1.00 & & 1.00 & \\
\hline & Spain & 1.29 & $1.11-1.50$ & 0.53 & $0.44-0.62$ \\
\hline
\end{tabular}

Secondary diagnosis

\begin{tabular}{|c|c|c|c|c|c|}
\hline \multirow[t]{2}{*}{ Hypertension } & No & 1.00 & & 1.00 & \\
\hline & Yes & 1.29 & $1.16-1.42$ & 0.86 & $0.75-0.97$ \\
\hline \multirow{2}{*}{ Hyperlipidemia } & No & 1.00 & & 1.00 & \\
\hline & Yes & 1.29 & $1.17-1.42$ & 0.82 & $0.72-0.93$ \\
\hline \multirow[t]{2}{*}{ Smoking } & No & 1.00 & & 1.00 & \\
\hline & Yes & 0.83 & $0.73-0.94$ & 1.15 & $0.99-1.34$ \\
\hline \multirow[t]{2}{*}{ Arrhythmias } & No & 1.00 & & & \\
\hline & Yes & 0.72 & $0.64-0.82$ & & \\
\hline \multirow[t]{2}{*}{ Heart failure } & No & 1.00 & & 1.00 & \\
\hline & Yes & 0.88 & $0.77-1.01$ & 1.16 & $0.98-1.38$ \\
\hline \multirow[t]{2}{*}{ COPD } & No & 1.00 & & 1.00 & \\
\hline & Yes & 0.56 & $0.47-0.69$ & 1.48 & $1.20-1.84$ \\
\hline \multirow{2}{*}{$\begin{array}{l}\text { Chronic renal } \\
\text { failure }\end{array}$} & No & 1.00 & & 1.00 & \\
\hline & Yes & 0.65 & $0.52-0.81$ & 1.39 & $1.07-1.81$ \\
\hline \multirow[t]{2}{*}{ Stroke } & No & 1.00 & & 1.00 & \\
\hline & Yes & 0.58 & $0.43-0.78$ & 2.02 & $1.46-2.79$ \\
\hline \multirow[t]{2}{*}{ Dementia } & No & 1.00 & & 1.00 & \\
\hline & Yes & 0.47 & $0.28-0.79$ & 2.53 & $1.55-4.13$ \\
\hline \multirow[t]{2}{*}{ Cancer } & No & 1.00 & & 1.00 & \\
\hline & Yes & 0.57 & $0.34-0.96$ & 2.08 & $1.20-3.60$ \\
\hline
\end{tabular}

a Model for 3 or more drugs: $n=7,453 ; P<0.0001 ;$ C-statistics: $0.634 ; P(x 2$ Hosmer-Lemeshow): 0.469; variables not significant with $P<0.05$ for entry and $P<0.10$ for removal: age 80 and over, diabetes and peripheral vascular disease. ${ }^{b}$ Model for 0 drugs: $n=7,453 ; P<0.0001$; C-statistics: 0.631; $P(x 2$ HosmerLemeshow): 0.037; variables not significant with $P<0.05$ for entry and $P<0.10$ for removal: age 80 and over, sex, other chronic IHD, diabetes, arrhythmias, and peripheral vascular disease.

$A M I=$ acute myocardial infarction; $C O P D=$ chronic obstructive pulmonary disease; $C I=$ confidence interval; $I H D=$ ischemic heart disease; $O R=$ odds ratio.

tant (i.e., from $-43 \%$ to $+65 \%$ patients reaching PDC75 with 3 or more drugs regarding the hospital in the median; Figure 2A) confidence intervals overlap except between the areas at the extremes. Interestingly, the correlation between both com- bined adherence measures is not exactly complementary, with some areas performing better in 1 measure than in the other.

\section{Discussion}

In this large population-based study of patients who experienced an ACS in the Valencia region, we found that ambulatory use of recommended medications after discharge was suboptimal. During the 9 months following discharge, only $69.9 \%$ of patients filled out enough prescriptions of antiplatelet drugs to cover $75 \%$ of the follow-up period. This figure was $45.4 \%$ for ACEI or ARB, $43.3 \%$ for beta-blockers, and $58.8 \%$ for statins. Only $47.6 \%$ of patients received 3 or more drugs, while $17.7 \%$ of patients received none of them. Worth noting is the lower adherence found in diagnoses other than MI, although other common predictors of nonadherence were found: older age, women, having copayment, foreign born, and many comorbid conditions (except for hypertension and hyperlipidemia, which were inversely associated, and diabetes and peripheral disease, which were not significantly associated). Additionally, health care delivery areas showed some degree of variability in their performance on these adherence measures that remained after the adjustment for covariates.

These figures are hardly comparable with other Spanish studies because they use prospective designs and measure the percentage of patients treated in a given moment of the followup (usually 6,12 , or 24 months after hospital discharge), not adherence during the follow-up period. Figures in our study seem to be at the upper limit of prescription post-discharge figures shown in observational cohort studies published in the last 10 years, ${ }^{22-24}$ except for antiplatelet agents (around 90\% in previous studies). Beyond that, this important discrepancy in the case of antiplatelet agents is probably due to aspirin, an over-the-counter and low price drug that can be purchased by patients with cash (not recorded in the VHA databases). In any case, current figures are lower than those reported in intervention studies (e.g., the PRESENTE study, which included an informative intervention in 110 Spanish hospitals reported, 6 months after hospital discharge, 94\% of patients taking antiplatelet agents, 59\% with beta-blockers, $48 \%$ with ACEI or ARB, and $87 \%$ with statins). ${ }^{25}$ Regarding studies with similar designs to the present study, Choudhry et al. (2008) reported, for lower income Medicare patients after MI, full adherence rates (defined as PDC80 within 90 days after discharge) of $46 \%$ with all 3 medications (beta-blockers, ACEI/ARB, and statins). ${ }^{10}$

Several factors were associated either positively or negatively with adherence to the medications reviewed. In our study, younger patients were less likely to adhere. Jackevicius et al. $(2008)^{26}$ found a similar association in Canadian patients, but other studies have shown lower adherence rates with increased age. $^{27,28}$ Age possibly confounds several variables (including gender, socioeconomic level, CHD severity, and comorbid conditions), and the association with adherence in each study relies on the specific characteristics of the population studied. In our study, gender was not significantly associated with adherence in the bivariable analysis but became significant 


\section{Adherence to Evidence-Based Therapies After Acute Coronary Syndrome: A Retrospective Population-Based Cohort Study Linking Hospital, Outpatient, and Pharmacy Health Information Systems in Valencia, Spain}

in the multivariate analysis, with lower adherence in women. This result is consistent with several studies on gender bias in CHD secondary prevention treatments, ${ }^{29-31}$ although in some studies, most of the gender-related differences disappear after age adjustment. 32,33

In other countries, studies have shown out-of-pocket expenses or copayments to be an important predictor of adherence. ${ }^{34-36}$ Because of the existence of a ceiling in payment for long-term medications, we did not expect large differences in adherence between patients with or without copayment, except for statins and antiplatelet agents (which have no ceiling and nonpensioners pay $40 \%$ of the drug price). In this sense, the results are consistent with our hypothesis except for ACEI/ $\mathrm{ARB}$, which showed the highest difference in adherence related to copayments (PDC75: 36.1 vs. 48.5). One possible explanation for this effect could be related to the absence of a ceiling in the case of ACEI or ARB in fixed-dose combinations with other drugs, a therapeutic alternative widely used in Spain. In any case, the financial burden of copayments is relatively modest in Spain-in global terms, copayments represent only a $6 \%$ of the regional governments' pharmaceutical expenditures. This factor could be partially confounded by other social determinants, such as educational level and family income. Understanding the relationship between social factors and adherence is an important topic that warrants further investigation. In this sense, the lower adherence of the immigrant population may be related to sociocultural, rather than economic factors, since immigrants without economic resources have the benefit of free pharmaceuticals.

We have found no studies comparing adherence between the different main diagnoses of ACS. Our finding of lower adherence in diagnoses other than MI is striking and may perhaps occur because physicians (or patients) consider these syndromes less important. This is probably an easily identifiable area for quality improvement. Regarding comorbidities, patients with certain comorbid conditions (hypertension and hyperlipidemia) were more likely to adhere to treatments, but other high-risk comorbidities did not show significant associations with adherence (diabetes and peripheral disease) or even seemed to increase the probability of drug discontinuation. This paradoxical behavior, with lower adherence among groups with the highest risk of poor outcomes, has been described in other studies ${ }^{37}$ and, in retrospective studies and at least partially, can be explained by the "sick stopper bias" (patients who stop therapy are often sicker than patients who do not, either because of true clinical differences or their lower likelihood of engaging in healthy activities). ${ }^{38}$ This phenomenon is similar in nature to the healthy user bias ${ }^{39}$ and, conversely, might help to explain some of the better outcomes of more adherent patients. Lower adherence figures in patients with dementia, cancer, or stroke reinforce the presence of a sick stopper bias. In the case of COPD, the relative (and controversial ${ }^{40}$ ) contraindication with beta-blockers should also be taken into account. Other patient-related factors occasionally associated with adherence not available in our study include baseline use of these drugs, patient attitudes and beliefs, ${ }^{41}$ perceived utility, ${ }^{42}$ role of social networks, ${ }^{43}$ health lit- eracy, ${ }^{44}$ and perception of medication safety. ${ }^{45}$

In addition to patient-specific factors, several organizational factors have been shown to be associated with medication adherence: drug prescription in the ACS hospital admission ${ }^{46}$ or at the time of discharge ${ }^{47}$ coordination of care between general practitioners and cardiologists and early outpatient follow-up visits, ${ }^{48}$ and discharge medication counseling. ${ }^{26}$ We have found no studies on geographical variation in adherence to CHD secondary prevention. In our study, health care delivery areas show a notable variability in adherence that remains after adjustment by a propensity score constructed with several covariables. This is an important organizational issue because it allows the targeting of improvement interventions on specific territories and the health care organizations serving those territories.

\section{Limitation}

Some potential limitations of this study should be addressed. First, our analysis has evaluated "all-comers," not just eligible patients without any contraindication. Information from administrative databases and ambulatory electronic medical records is limited to evaluating many variables that influence adherence (i.e., a patient's motivation or certain side effects such as fatigue or sexual dysfunction). Therefore, the real number of patients eligible for pharmacological secondary prevention is probably lower than the figures shown, and our study possibly overestimates the potential opportunity to improve adherence. Second, we use dispensation claims as a measure of adherence, but patients do not consume all the drugs dispensed. Nevertheless, studies on concordance between claims-based measures and pill counts in cardiovascular disease show a high concordance, ${ }^{49}$ and we can expect a high consistency between dispensation and patient consumption. Nonetheless, some degree of overestimation of adherence should be expected. On the other hand, a slight underestimation is expected because of the nonexclusion of hospitalization days from the PDC denominator. Third, pharmacies in Spain are not too strict in fulfilling the requirement of a prescription for dispensing cardiovascular medications, and it is possible to obtain them without prescription forms. While we think the amount of clopidogrel, beta-blockers, ACEI/ARB, or statins acquired without prescription will be low, many patients may purchase aspirin over the counter without a prescription, and, thus, the use of aspirin could not be reliably captured in the administrative dispensation databases. Fourth, dispensations obtained prior to hospital discharge or from pharmacies outside the Valencia autonomous community (e.g., on holidays outside the region) have not been recorded in our study. Fifth, the categorization of adherent patients based on a PDC $\geq 75$ is somewhat arbitrary. This dichotomization, however, was consistent with the literature that typically uses a PDC cut-off point of $80 \%$. We opted for a PDC75 because in the Spanish prescription system, with a follow-up of 9 months and for most of the medications analyzed, a cut-off point of $80 \%$ becomes a factual cut-off point near $90 \%$ (8 packages with doses typically for 1 month in 9 months $=88.9 \%$ of days covered). The chosen PCD75 ( 7 packages in 9 months $=77.8 \%$ of days covered) was 


\section{Adherence to Evidence-Based Therapies After Acute Coronary Syndrome: A Retrospective Population-Based Cohort Study Linking Hospital, Outpatient, and Pharmacy Health Information Systems in Valencia, Spain}

more comparable to the commonly used PCD80.

Regarding the external validity of our results, the current study was conducted in a specific region. Given the potential differences with other regions or countries (an important variation among areas within the same region and served by the same health care organization has been shown), the generalization of our findings to other jurisdictions should be done with caution.

\section{Conclusions}

Nonadherence to evidence-based medical therapies in postACS follow-up is a significant source of avoidable mortality, morbidity, and health care expenditure..$^{50}$ Our results suggest that the proportion of fully adherent patients remains suboptimal and that important improvements are still possible in the quality of IHD care. Areas for future focus include the use of health information systems to monitor achievements and to evaluate the effectiveness of quality improvement interventions in specific contexts.

\section{Authors}

GABRIEL SANFÉLIX-GIMENO, PharmD, PhD, is Researcher, Health Services Research Unit, Center for Public Health Research (CSISP-FISABIO), Valencia, Spain, Red de Investigación en Servicios de Salud en Enfermedades Cronicas (REDISSEC); SALVADOR PEIRÓ, MD, PhD, is Senior Researcher and Head, Health Services Research Unit, Center for Public Health Research (CSISP-FISABIO), Valencia, Spain, Red de Investigación en Servicios de Salud en Enfermedades Cronicas (REDISSEC); INMA FERREROS, BSc, is Biostatistician, Health Services Research Unit, Center for Public Health Research (CSISP-FISABIO), Valencia, Spain, Red de Investigación en Servicios de Salud en Enfermedades Cronicas (REDISSEC); RAQUEL PÉREZ-VICENTE, BSc, is Biostatistician, Health Services Research Unit, Center for Public Health Research (CSISP-FISABIO), Valencia, Spain; JULIÁN LIBRERO, MD, PhD, is Senior Researcher, Health Services and Policy Research Unit, Health Sciences Institute in Aragon (I+CS), Spain, Health Services Research Unit, Center for Public Health Research (CSISP-FISABIO), Valencia, Spain, Red de Investigación en Servicios de Salud en Enfermedades Cronicas (REDISSEC); FERRÁN CATALÁ-LÓPEZ, PharmD, $P h D$, is Associate Researcher, Health Services Research Unit, Center for Public Health Research (CSISP-FISABIO), Valencia, Spain; FRANCISCO ORTIZ, MD, is Chief, Healthcare Assurance Service, Valencia Health Agency, Spain, Red de Investigación en Servicios de Salud en Enfermedades Cronicas (REDISSEC); and VICENT TORTOSA-NÁCHER, MD, is Vice-Chief, Healthcare Assurance Service, Valencia Health Agency, Spain, Red de Investigación en Servicios de Salud en Enfermedades Cronicas (REDISSEC).

AUTHOR CORRESPONDENCE: Gabriel Sanfélix-Gimeno, PharmD, PhD, Centro Superior de Investigación en Salud Pública (CSISP), Health Services Research Unit, Avda. de Cataluña 21. 46020 Valencia, Spain. Tel.: +34 9619255972; Fax: +34 961925703; E-mail: sanfelix_gab@gva.es; sanfelix@hsph.harvard.edu.

\section{DISCLOSURES}

This study was financed by grants 678/2007 and 011/2011 from the Department of Health of the Valencia Government.

The authors reported no financial or other potential conflicts of interest related to the subject of this manuscript.

Concept and design were performed by Sanfélix-Gimeno, Peiró, Ferreros, Pérez-Vicente, and Librero. Data were collected by Ortiz, Tortosa-Nácher Sanfélix-Gimeno, Peiró, Ferreros, and Librero. Data were interpreted by PérezVicente, Librero, Sanfélix-Gimeno, Peiró, Catalá-López, and Ferreros. The manuscript was written by Sanfélix-Gimeno, Peiró, Pérez-Vicente, Ferreros, Catalá-López, Ortiz, and Tortosa-Nácher, and revised by Ferreros, CataláLópez, Sanfélix-Gimeno, and Peiró.

\section{REFERENCES}

1. Yeh RW, Sidney S, Chandra M, Sorel M, Selby JV, Go AS. Population trends in the incidence and outcomes of acute myocardial infarction. N Engl J Med. 2010;362(23):2155-65. Available at: http://www.nejm.org/doi/ full/10.1056/NEJMoa0908610. Accessed March 10, 2013.

2. Instituto Nacional de Estadística. Defunciones según la causa de muerte 2009. Defunciones por causas (lista reducida), sexo y edad. Available at: http://www.ine.es. Accessed March 10, 2013.

3. Mathers C, Boerma T, Ma Fat D. The global burden of disease: 2004 update. Geneva: World Health Organization; 2008. Available at: http://www. who.int/healthinfo/global_burden_disease/GBD_report_2004update_full. pdf. Accessed March 10, 2013.

4. Smith SC Jr, Allen J, Blair SN, et al. AHA/ACC guidelines for secondary prevention for patients with coronary and other atherosclerotic vascular disease: 2006 update: endorsed by the National Heart, Lung, and Blood Institute. Circulation. 2006;113(19):2363-72. Available at: http://circ.ahajournals.org/content/113/19/2363.long. Accessed March 10, 2013.

5. Wald NJ, Law MR. A strategy to reduce cardiovascular disease by more than 80\%. BMJ. 2003;326(7404):1419. Available at: http://www.ncbi.nlm. nih.gov/pmc/articles/PMC162259/?tool=pubmed. Accessed March 10, 2013

6. Ford ES, Ajani UA, Croft JB, et al. Explaining the decrease in U.S. deaths from coronary disease, 1980-2000. N Engl J Med. 2007;356(23):2388-98. Available at: http://www.nejm.org/doi/full/10.1056/NEJMsa053935. Accessed March 10, 2013.

7. Kulik A, Shrank WH, Levin R, Choudhry NK. Adherence to statin therapy in elderly patients after hospitalization for coronary revascularization. Am J Cardiol. 2011;107(10):1409-14.

8. Kotseva K, Wood D, De Backer G, De Bacquer D, Pyörälä K, Keil U; EUROASPIRE Study Group. EUROASPIRE III: a survey on the lifestyle, risk factors and use of cardioprotective drug therapies in coronary patients from 22 European countries. Eur J Cardiovasc Prev Rehabil. 2009;16(2):121-37.

9. Austin PC, Tu JV, Ko DT, Alter DA. Factors associated with the use of evidence-based therapies after discharge among elderly patients with myocardial infarction. CMAJ. 2008;179(9):901-08. Available at: http://www.ncbi.nlm. nih.gov/pmc/articles/PMC2565714/?tool=pubmed. Accessed March 10, 2013.

10. Choudhry NK, Setoguchi S, Levin R, Winkelmayer WC, Shrank WH. Trends in adherence to secondary prevention medications in elderly post-myocardial infarction patients. Pharmacoepidemiol Drug Saf. 2008;17(12):1189-96. Available at: http://www.ncbi.nlm.nih.gov/pmc/articles/PMC2680489/?tool=pubmed. Accessed March 10, 2013.

11. Gislason GH, Rasmussen JN, Abildstrøm SZ, et al. Long-term compliance with beta-blockers, angiotensin-converting enzyme inhibitors, and statins after acute myocardial infarction. Eur Heart J. 2006;27(10):1153-38. Available at: http://eurheartj.oxfordjournals.org/content/27/10/1153.long. Accessed March 10, 2013.

12. Sanfélix G, Peiró S, Gosalbes-Soler V, Cervera-Casino P. The secondary prevention of ischaemic heart disease in Spain. A systematic review of observational studies. Aten Primaria. 2006;38(5):250-57. [Article in Spanish] 


\section{Adherence to Evidence-Based Therapies After Acute Coronary Syndrome: A Retrospective Population-Based Cohort Study Linking Hospital, Outpatient, and Pharmacy Health Information Systems in Valencia, Spain}

13. Choudhry NK, Winkelmayer WC. Medication adherence after myocardial infarction: a long way left to go. J Gen Intern Med.

2008;23(2):216-18. Available at: http://www.ncbi.nlm.nih.gov/pmc/articles/ PMC2359176/?tool=pubmed. Accessed March 10, 2013.

14. Ho PM, Magid DJ, Shetterly SM, et al. Medication nonadherence is associated with a broad range of adverse outcomes in patients with coronary artery disease. Am Heart J. 2008;155(4):772-79.

15. Setoguchi S, Glynn RJ, Avorn J, Mittleman MA, Levin R, Winkelmayer WC. Improvements in long-term mortality after myocardial infarction and increased use of cardiovascular drugs after discharge: a 10-year trend analysis J Am Coll Cardiol. 2008;51(13):1247-54.

16. Rasmussen JN, Chong A, Alter DA. Relationship between adherence to evidence-based pharmacotherapy and long-term mortality after acute myocardial infarction. JAMA. 2007;297(2):177-86.

17. Austin PC, Mamdani MM, Juurlink DN, Alter DA, Tu JV. Missed opportunities in the secondary prevention of myocardial infarction: an assessment of the effects of statin underprescribing on mortality. Am Heart J. 2006;151(5):969-75.

18. Mukherjee D, Fang J, Chetcuti S, Moscucci M, Kline-Rogers E, Eagle KA. Impact of combination evidence-based medical therapy on mortality in patients with acute coronary syndromes. Circulation. 2004;109(6):745-49. Available at: http://circ.ahajournals.org/content/109/6/745.long. Accessed March 10, 2013.

19. Martin-Moreno JM, Alonso P, Claveria A, Gorgojo L, Peiró S. Spain: a decentralised health system in constant flux. BMJ. 2009;338:bl170.

20. Caetano PA, Lam JM, Morgan SG. Toward a standard definition and measurement of persistence with drug therapy: examples from research on statin and antihypertensive utilization. Clin Ther. 2006;28(9):1411-24

21. Steiner JF, Prochazka AV. The assessment of refill compliance using pharmacy records: methods, validity, and applications. J Clin Epidemiol. 1997;50(1):105-16.

22. Brotons Cuixart C, Moral Peláez I, Permanyer Miralda G, Ribera Solé A, Cascant Castelló P; Estudio CIRCORCA. Therapeutic control and quality of life in coronary artery bypass surgery patients. Med Clin (Barc). 2001;116(7):241-15. [Article in Spanish]

23. Grupo de Investigación del estudio PREMISE. Secondary prevention of myocardial infarction and health-related quality of life. Med Clin (Barc). 2002;119(1):9-12. [Article in Spanish]

24. EUROASPIRE II Study Group. Lifestyle and risk factor management and use of drug therapies in coronary patients from 15 countries: principal results from EUROASPIRE II Euro Heart Survey Programme. Eur Heart J. 2001;22(7):554-72. Available at: http://eurheartj.oxfordjournals.org/content/22/7/554.full.pdf+html. Accessed March 10, 2013.

25. de Velasco JA, Cosín J, de Oya M, de Teresa E; Grupo de investigadores del estudio PRESENTE. Intervention program to improve secondary prevention of myocardial infarction. Results of the PRESENTE (early secondary prevention) study. Rev Esp Cardiol. 2004;57(2):146-54. [Article in Spanish]

26. Jackevicius CA, Li P, Tu JV. Prevalence, predictors, and outcomes of primary nonadherence after acute myocardial infarction. Circulation. 2008;117(8):1028-36. Available at: http://circ.ahajournals.org/content/ 117/8/1028.long. Accessed March 10, 2013.

27. Lee HY, Cooke CE, Robertson TA. Use of secondary prevention drug therapy in patients with acute coronary syndrome after hospital discharge. J Manag Care Pharm. 2008;14(3):271-80. Available at: http://www.amcp.org/ data/jmcp/JMCPMaga_April08_271-280.pdf.

28. Tran CT, Laupacis A, Mamdani MM, Tu JV. Effect of age on the use of evidence-based therapies for acute myocardial infarction. Am Heart J. 2004;148(5):834-41.
29. Di Cecco R, Patel U, Upshur RE. Is there a clinically significant gender bias in post-myocardial infarction pharmacological management in the older $(>60)$ population of a primary care practice? BMC Fam Pract. 2002;3:8. Available at: http://www.ncbi.nlm.nih.gov/pmc/articles/ PMC111196/?tool=pubmed. Accessed March 10, 2013.

30. Hippisley-Cox J, Pringle M, Crown N, Meal A, Wynn A. Sex inequalities in ischaemic heart disease in general practice: cross sectional survey. BMJ. 2001;322(7290):832. Available at: http://www.ncbi.nlm.nih.gov/pmc/ articles/PMC30561/?tool=pubmed. Accessed March 10, 2013.

31. Simpson CR, Hannaford PC, Williams D. Evidence for inequalities in the management of coronary heart disease in Scotland. Heart. 2005;91(5):630-34. Available at: http://www.ncbi.nlm.nih.gov/pmc/articles/ PMC1768874/?tool=pubmed. Accessed March 10, 2013.

32. Williams RI, Fraser AG, West RR. Gender differences in management after acute myocardial infarction: not 'sexism' but a reflection of age at presentation. J Public Health (Oxf). 2004;26(3):259-63. Available at: http://jpubhealth.oxfordjournals.org/content/26/3/259.long. Accessed March 30, 2013.

33. Cruz I, Serna C, Real J, Galindo G, Gascó E, Galván L. Ischemic heart disease and primary care: identifying gender-related differences. An observational study. BMC Fam Pract. 2008;9:60. Available at: http://www.ncbi.nlm. nih.gov/pmc/articles/PMC2584632/?tool=pubmed. Accessed March 10, 2013.

34. Choudhry NK, Brennan T, Toscano M, et al. Rationale and design of the Post-MI FREEE trial: a randomized evaluation of first-dollar drug coverage for post-myocardial infarction secondary preventive therapies. Am Heart J. 2008;156(1):31-36. Available at: http://www.ncbi.nlm.nih.gov/pmc/articles/ PMC2697130/?tool=pubmed. Accessed March 10, 2013.

35. Schneeweiss S, Patrick AR, Maclure M, Dormuth CR, Glynn RJ. Adherence to statin therapy under drug cost sharing in patients with and without acute myocardial infarction: a population-based natural experiment. Circulation. 2007;115(16):2128-35. Available at: http://circ.ahajournals.org/ content/115/16/2128.long. Accessed March 10, 2013.

36. Doshi JA, Zhu J, Lee BY, Kimmel SE, Volpp KG. Impact of a prescription copayment increase on lipid-lowering medication adherence in veterans. Circulation. 2009;119(3):390-97. Available at: http://www.ncbi.nlm.nih.gov/ pmc/articles/PMC2753258/?tool=pubmed. Accessed March 10, 2013.

37. Newby LK, LaPointe NM, Chen AY, et al. Long-term adherence to evidence-based secondary prevention therapies in coronary artery disease. Circulation. 2006;113(2):203-12. Available at: http://circ.ahajournals.org/content/113/2/203.long. Accessed July 18, 2012.

38. Choudhry NK. Improving the pathway from cardiovascular medication prescribing to longer-term adherence: new results about old issues. Circ Cardiovasc Qual Outcomes. 2010;3(3):223-25. Available at: http://circoutcomes.ahajournals.org/content/3/3/223.long. Accessed March 10, 2013.

39. Dormuth CR, Patrick AR, Shrank WH, et al. Statin adherence and risk of accidents: a cautionary tale. Circulation. 2009;119(15):2051-57. Available at: http://www.ncbi.nlm.nih.gov/pmc/articles/PMC2744446/?tool=pubmed. Accessed March 10, 2013.

40. Short PM, Lipworth SI, Elder DH, Schembri S, Lipworth BJ. Effect of beta blockers in treatment of chronic obstructive pulmonary disease: a retrospective cohort study. BMJ. 2011;342:d2549. Available at: http://www.ncbi.nlm. nih.gov/pmc/articles/PMC3091487/?tool=pubmed. Accessed March 10, 2013.

41. Gatti ME, Jacobson KL, Gazmararian JA, Schmotzer B, Kripalani S. Relationships between beliefs about medications and adherence. Am J Health Syst Pharm. 2009;66(7):657-64.

42. Kripalani S, Henderson LE, Jacobson TA, Vaccarino V. Medication use among inner-city patients after hospital discharge: patient-reported barriers and solutions. Mayo Clin Proc. 2008;83(5):529-35.

43. Molloy GJ, Perkins-Porras L, Strike PC, Steptoe A. Social networks and partner stress as predictors of adherence to medication, rehabilitation attendance, and quality of life following acute coronary syndrome. Health Psychol. 2008;27(1):52-58 
44. Kripalani S, Gatti ME, Jacobson TA. Association of age, health literacy, and medication management strategies with cardiovascular medication adherence. Patient Educ Couns. 2010;81(2):177-81.

45. Reaume KT, Erickson SR, Dorsch MP, et al. Effects of cerivastatin withdrawal on statin persistence. Ann Pharmacother. 2008;42(7):956-61.

46. Amar J, Ferrières J, Cambou JP, Amelineau E, Danchin N. Persistence of combination of evidence-based medical therapy in patients with acute coronary syndromes. Arch Cardiovasc Dis. 2008;101(5):301-06.

47. Danchin N, Diévart F, Thébaut JF, et al. Predictors of long-term use of evidence-based therapies after non-ST-segment elevation acute coronary syndrome. The S-Témoin survey. Int J Cardiol. 2009;133(1):32-40.
48. Daugherty SL, Ho PM, Spertus JA, et al. Association of early follow-up after acute myocardial infarction with higher rates of medication use. Arch Intern Med. 2008;168(5):485-91

49. Grymonpre R, Cheang M, Fraser M, Metge C, Sitar DS. Validity of a prescription claims database to estimate medication adherence in older persons. Med Care. 2006;44(5):471-77.

50. Ho PM, Bryson CL, Rumsfeld JS. Medication adherence: its importance in cardiovascular outcomes. Circulation. 2009;119(23):3028-35. Available at: http:// circ.ahajournals.org/content/119/23/3028.long. Accessed March 10, 2013. 